\title{
Pregnant women adherence level to antenatal care visit and its effect on perinatal outcome among mothers in Tigray Public Health institutions, 2017: cohort study
}

\author{
Abera Haftu, Hadgay Hagos, Mhiret-AB Mehari and Brhane G/her
}

\begin{abstract}
Objective: To assess pregnant women adherence level to antenatal care visit and its effect on perinatal outcome among mothers in Tigray Public Health institutions, 2017.

Results: The overall adherence level of the women towards to antenatal care visit was $49.9 \%$ and incidence of PPH, still birth, early neonatal death, late neonatal death and low birth weight complication was 4.3\%, 2.3\%, 2.7\%, 1.9\% and $7.5 \%$ respectively. PPH, preterm labor, early neonatal death and LBW complication was reduced by $81.2 \%, 52 \%, 61 \%$ and $46 \%$ respectively among women's with complete adherence to ANC visit.
\end{abstract}

Keywords: Pregnant women, Adherence, Antenatal care

\section{Introduction}

Complications that happen during pregnancy and childbirth are the most leading causes of maternal mortality and morbidity among women whose age ranges from 15 to 49 in developing countries [1]. Annually around 287,000 women die secondary to pregnancy related cause in the globe, among this figure $99 \%$ of the maternal death is from underdeveloped countries [2]. Ethiopia is among the leading countries with high maternal mortality and morbidity from the developing countries [3]. In developing countries almost all pregnant women's receive antenatal care at least once, but in sub-Saharan countries the report is around $68 \%$ where women's take antenatal care (ANC) services at least ones and majority of them visit the health institutions at third visit $[4,5]$.

Most research finding showed that most of maternal and neonatal deaths are preventable; one the strategic and important key step for reducing of maternal related mortality and morbidity is antenatal care directly by detecting and treating of complications in earlier period

\footnotetext{
*Correspondence: aberahaftu@gmail.com
}

Department of Midwifery, Mekele University College of Health Sciences, Tigray, Ethiopia starting from the onset of pregnancy till delivery [6]. The timing of starting first ANC and total number of ANC visits that pregnant women receive and not attending the recommend ANC services may lead to adverse perinatal outcomes [7].

Ethiopian Demographic Health Survey (EDHS) 2016 showed that national ANC service coverage is around $64 \%$, even if the total number of ANC visit is good, starting ANC follow up in the earlier second trimester is low in magnitude. Research results of late ANC service booking from Addis Ababa, Metekel, Hadiya, Ambo and Gondar was $59.8 \%, 55.1 \%, 68.2 \%, 86.8 \%$ and $64.9 \%$ respectively [8-12]. In the current situation Ethiopia deliveries three tiered health care system; this is characterized by district health system, health centers and health posts which are connected to each other by referral system [13]. The need of ANC is taken as basic rights of all pregnant women's to keep safe their infants, the high maternal and neonatal mortality in Ethiopia is the result of poor utilization of ANC [14, 15]. The primary target of ANC is to detect problem, treat on time and prevention of complications by health care provision, despite of this illiteracy and low socio economic status contribute to poor ANC adherence. There have many studies which showed positive 
effect of ANC on perinatal outcome including reducing risk of postpartum hemorrhage (PPH), low birth weight, preterm birth and perinatal death. World health organization (WHO) recommended for all pregnant women to have four consecutive ANC visits for low risk pregnant women's [16-25].

\section{Main text}

Methods and materials

\section{Study area and period}

The study will be conducted in Tigray Public Health institutions. Tigray is located in Northern part of Ethiopia and around $783 \mathrm{~km}$ away from the capital city Addis Ababa. Around 5.5 million people are found in this region (census 2007). The region is the owner of 216 health centers, 15 General Hospitals and 2 Referral Hospitals. Among the selected zones (southern, Mekele \& southeastern zones) there are about 61 health centers, 5 primary Hospitals 1 Referral Hospital and 6 General Hospitals. The study was conducted from July 1, 2017 to August 2018.

\section{Study design}

Prospective cohort design was employed.

\section{Source population}

All women's who gave birth in Tigray Public Health institutions.

Study population Women's who fulfill the criteria and selected in the study period.

Exposed group Are mothers coming to the health facility for delivery services where their ANC visit was complete.

Non-exposed group Are mothers coming to the health facility for delivery services where their ANC visit was incomplete.

\section{Eligibility criteria}

Inclusion criteria All women coming for delivery services in the public health facilities.

Exclusion criteria Women who has known medical illness (hypertension, cardiac disease, DM, malaria, liver disease).

\section{Sample size determination}

Sample size was calculated using double population proportion formula for cohort study considering the following assumptions:

$\mathrm{CL}=95 \%$.

Power-80\%.

A one-to-one ratio of exposure to non-exposure.

Since there is no any documented evidence in the setting, it is assumed that the complication rate will be twice as high amongst the exposed group (complete adherence) as compared to unexposed group (incomplete adherence).

By taking prevalence of pregnancy complication (PIH/preeclampsia-eclampsia) among the mothers with complete adherence to be $5.1 \%$ from previous study in Ghana [11].

$$
n_{1}=\frac{\left[Z_{\alpha / 2} \sqrt{\left(1+\frac{1}{r}\right) P(1-P)}-Z_{\beta \sqrt{P_{1}\left(1-P_{1}\right)+\frac{P_{2}\left(1-P_{2}\right)}{r}}}\right]^{2}}{\left(P_{1}-P_{2}\right)^{2}}
$$

The final total sample size is 928 .

464 participants in each group.

\section{Sampling technique}

Systematic random sampling was used for this population and the sample was distributed to each facility based on proportional allocation in correspondence of delivery services. Women who have full visits were considered as exposed group where as those with incomplete follow up will be considered as non exposed group. Exposed and non exposed mothers who fulfill the inclusion criteria were enrolled to the cohort and were followed until the end of post partum period. Among the seven zones of the region $40 \%$ of them were selected by simple random selection technique. In the selected zones there are about 73 health facilities, by using simple lottery method 20 of them will be selected. The sample size will be distributed to each selected health facility by probability proportion to size (PPS) according to their ANC flow rate.

\section{Data collection technique and process}

Women's who come for delivery services in the public health institutions who met the criteria for the cohort study were enrolled and followed till the end of the postpartum period. After reviewing the women's document based on their ANC frequency they were recruited to exposed and non exposed groups, those with complete adherence ANC visits were considered as exposed groups and those incomplete ANC visits were considered as non exposed groups. Questioner was prepared from different literatures and WHO recommendations for pregnancy, delivery and post delivery continuum of care. There were about 20 BSC Midwives data collectors one data collector per each health facility. Three day data training was given to the data collectors and frequent supervision was made to each health facilities at 1 week interval. The follow up was at respective health institutions, but for those who were unable to attend the follow up health facility required information was collected by telephone. In 
order to ensure adherence of the follow up the community was mobilized by health extension workers

Data was entered by Epi data version 3.1 software first then exported to SPSS version 20 software for analysis purpose. Descriptive analysis was presented using mean and proportions. Tables, figures and text were used for data presentation. Determinants of maternal and neonatal complications, as well as the effect of complete adherence on pregnancy outcomes was estimated and expressed as relative risks (RRs) with their 95\% confidence intervals $(\mathrm{CI})$. Binary logistic regression run to see the association between variables. Significance was declared at $p$ value $<0.05$.

\section{Data quality assurance}

Standardized English version measuring questionnaire was adapted and it was translated into Tigrigna (local language) by experts. The questionnaire was reviewed by senior researchers and comments were incorporated for internal validity. In addition it was pre-tested on $10 \%$ of the calculated sample size. Data collectors and supervisors were trained for 3 days on the tools and process of data collection. Five percent of the collected data was checked by the supervisor for completeness and finally the investigators will monitor the overall quality of data collection.

\section{Variables}

Dependent variable Perinatal outcome.

Independent variable Socio-demographic factors (age, educational level, marital status and employment status).

Maternal factors (parity, trimester at first antenatal care visit, previous pregnancy history and number of times antenatal clinic was attended during pregnancy).

Neonatal factors (mode of delivery, duration of delivery, place of birth).

\section{Operational definitions}

Complete adherence women's who attend the ANC visit four and above.

Incomplete adherence women who had attended ANC visit less than or equal to three time.

\section{Results}

A total of 1103 women were recruited and $100 \%$ of them were followed up to 6 weeks post-partum from December 2017 to July 2018. The number of women's enrolled to the exposed and non exposed groups were above the minimum size set during the proposal writing, this is done to meet the minimum number of participants to each groups in the selected health institutions.

\section{Participants' baseline characteristics}

The age of the participants in mean and standard deviation were 26.4 (5.2) years. $45.3 \%$ of the participants' age was 19-25 years. Most of the participants' educational level were secondary school and above which makes 42.3\% from the total. More than half of the participants (71.8\%) were from urban residence and married individuals take the highest proportions (92.7\%) from the total participants (see Table 1).

\section{Incidence of maternal and neonatal complications}

Overall the incidence of postpartum hemorrhage is $4.8 \%$ of which $1.6 \%$ and $6.9 \%$ are from women's with complete and incomplete adherence respectively. Still birth and asphyxia were $2.3 \%$ and $10.3 \%$ consecutively (see Table 2).

\section{Effect of complete adherence on risk of pregnancy complications}

Postpartum hemorrhage complication was reduced by $81.2 \%$ among women's with complete adherence to antenatal care visit $[\mathrm{ARR}=\mathrm{CI} 95 \%=0.188(0.088$ $0.404)]$. Early neonatal death was reduced by $61.3 \%$ $[\mathrm{ARR}=\mathrm{CI} 95 \%=0.387(0.162-0.928)]$ and low birth weight was reduced by $46.5 \%$ [ARR $=$ CI $95 \%=0.535$ (0.326-0.878)] among women's with complete adherence to antenatal visit (see Table 3).

\section{Discussion}

Many studies have shown the positive effect of antenatal care services on perinatal outcome, so giving emphasis to determine the gap with women adherence to antenatal visit and its effect on perinatal outcome is timely and significant as woman with single visit and four visits will not have similar complications.

Overall the women's adherence to complete visit to antenatal care is $49.9 \%$ and the follow up till postpartum period was $100 \%$ complete in our study where as research findings from Addis Ababa, Metekel, Hadya Zone, Ambo and Gonder show that the prevalence of ANC service booking was 59.8\%, 55.1\%, 68.2\%, 86.8\% and $64.9 \%$, respectively [8-12]. This variation could due to the geographical location and the documentation system and manly the study design in general as they use the snap shoot kind of study where as in this study the focus was on the full course of the antenatal care.

In this study women's who attend at least single antenatal care was much lower than other studies (7\%) which was done in Nepal, Pakistan, Bangladesh and Indian which was $28 \%, 28 \%, 33 \%$ and $60 \%$ respectively [26]. This variation again could be due to the educational level and economic status of the participants. 
Table 1 Socio demographic characteristics of study participants

\begin{tabular}{|c|c|c|}
\hline Variable & Frequency & Percent \\
\hline \multicolumn{3}{|l|}{ Age } \\
\hline$\leq 18$ & 33 & 3 \\
\hline $19-25$ & 500 & 45.3 \\
\hline $26-30$ & 356 & 32.3 \\
\hline $31-35$ & 156 & 14.1 \\
\hline$\geq 36$ & 58 & 5.3 \\
\hline \multicolumn{3}{|l|}{ Residence } \\
\hline Urban & 729 & 71.8 \\
\hline Rural & 311 & 28.2 \\
\hline \multicolumn{3}{|l|}{ Marital status } \\
\hline Married & 1023 & 92.7 \\
\hline Single & 52 & 4.7 \\
\hline Divorced & 23 & 2.1 \\
\hline Widowed & 5 & 0.5 \\
\hline \multicolumn{3}{|l|}{ Religion } \\
\hline Orthodox & 1011 & 91.7 \\
\hline Muslim & 79 & 7.2 \\
\hline Catholic & 5 & 0.5 \\
\hline Protestant & 8 & 0.7 \\
\hline \multicolumn{3}{|l|}{ Educational level } \\
\hline No education & 283 & 25.7 \\
\hline Read and write & 99 & 9 \\
\hline Primary school & 254 & 23 \\
\hline Secondary school and above & 467 & 42.3 \\
\hline \multicolumn{3}{|l|}{ Occupation } \\
\hline House wife & 729 & 66.1 \\
\hline Government employee & 157 & 14.2 \\
\hline Nongovernmental employee & 34 & 3.1 \\
\hline Private organization & 147 & 13.3 \\
\hline Daily laborer & 17 & 1.5 \\
\hline Other & 19 & 1.7 \\
\hline \multicolumn{3}{|l|}{ Ethnicity } \\
\hline Tigray & 1088 & 98.6 \\
\hline Amahara & 13 & 1.2 \\
\hline Other & 2 & 0.2 \\
\hline \multicolumn{3}{|l|}{ Monthly income (birr) } \\
\hline$\leq 500$ & & 4.5 \\
\hline $501-1500$ & 64 & 5.8 \\
\hline $1501-3000$ & 310 & 28.1 \\
\hline $3001-5000$ & 351 & 31.8 \\
\hline $5001-1000$ & 203 & 18.4 \\
\hline$\geq 10,001$ & 153 & 13.9 \\
\hline
\end{tabular}

In this study the incidence of low birth weight was $7.5 \%$ which is a little bit higher than a study done in Nigeria which was $4.8 \%$ among women's with greater than or equal to four visits [27] and this variation could
Table 2 Incidence of the maternal and neonatal complications among the two groups (adhered versus non adhered)

\begin{tabular}{lccc}
\hline Complication & $\begin{array}{l}\text { Incidence (\%) } \\
\mathbf{N = 1 1 0 3}\end{array}$ & $\begin{array}{l}\text { Complete } \\
\text { adherence } \\
\mathbf{N = 5 5 0}\end{array}$ & $\begin{array}{l}\text { Incomplete } \\
\text { adherence } \\
\mathbf{N = 5 5 3}\end{array}$ \\
\hline $\begin{array}{l}\text { Maternal } \\
\text { PPH }\end{array}$ & $47(4.3)$ & $9(1.6)$ & $38(6.9)$ \\
Maternal infection & $90(8.2)$ & $34(6.2)$ & $56(10.1)$ \\
Admitted to ICU & $28(2.5)$ & $13(2.4)$ & $15(2.7)$ \\
Incomplete postnatal visit & $452(41)$ & $170(30.9)$ & $282(50.9)$ \\
Neonatal & & & \\
Still birth & $25(2.3)$ & $5(0.9)$ & $20(3.6)$ \\
Neonatal sepsis & $111(10.1)$ & $55(10)$ & $56(10.1)$ \\
Early neonatal death & $30(2.7)$ & $8(1.5)$ & $22(4)$ \\
Late neonatal death & $21(1.9)$ & $6(1.1)$ & $15(2.7)$ \\
Asphyxia & $114(10.3)$ & $49(8.9)$ & $65(11.8)$ \\
Low birth weight & $83(7.5)$ & $31(5.6)$ & $52(9.4)$ \\
\hline
\end{tabular}

be due the nutritional consumption and geographical location.

Most studies from what we had searched showed that prevalence and determinant factor for ANC utilization, less emphasis was given to women's level of adherence to ANC visits and its effect on perinatal outcome. The incidence of developing postpartum hemorrhage among women's with complete adherence to antenatal care visit was about $1.6 \%$ where as in women's with incomplete adherence was $6.9 \%$ and incidence of adherence to postnatal visit was $30.9 \%$ and $50.9 \%$ among women's with complete and incomplete adherence respectively.

This study shows that incidence of neonatal complication is higher among the women's neonate with incomplete adherence to antenatal visit. Incidence of still birth among women's with incomplete adherence is four fold of the women's with complete adherence to antenatal visit which is 3.6 and $0.9 \%$ respectively. The incidence of early neonatal death and late neonatal death among women's with complete adherence to antenatal visit was almost similar which is 1.5 and $1.1 \%$ respectively where as among the women's with incomplete adherence to antenatal care visit the incidence of the early neonatal death is higher than the late neonatal death which is 4 and 2.7\% consecutively and this could be due to the vulnerability of the neonate to many things in the earlier period than late after they customize the environment. The incidence of low birth weight among the non exposed group was almost twice of the exposed group (9.4\%:5.6\%) and this might be probably due to the counseling regarding nutritional methods during antenatal visit. 
Table 3 Multivariate analysis of complete adherence's effect on maternal and neonatal complications

\begin{tabular}{|c|c|c|c|c|}
\hline Complication & Crude RR 95\% Cl & p-value & Adjusted RR 95\% Cl & p-value \\
\hline $\mathrm{PPH}$ & $0.225(0.108-0.471)$ & 0.000 & $0.188(0.088-0.404)$ & 0.000 \\
\hline Preterm labor & $0.425(0.267-0.673)$ & 0.000 & $0.476(0.290-0.783)$ & 0.003 \\
\hline Maternal sepsis & $1.73(1.110-2.696)$ & 0.015 & $1.610(0.986-2.630)$ & 0.057 \\
\hline Neonatal sepsis & $1.026(0.693-1.520)$ & 0.896 & $0.833(0.544-1.275)$ & 0.400 \\
\hline Early neonatal death & $0.356(0.157-0.807)$ & 0.013 & $0.387(0.162-0.928)$ & 0.033 \\
\hline Late neonatal death & $0.396(0.152-1.027)$ & 0.057 & $0.380(0.138-1.052)$ & 0.060 \\
\hline Low birth weight & $0.575(0.363-0.913)$ & 0.019 & $0.535(0.326-0.878)$ & 0.013 \\
\hline Delivery complication & $1.173(0.922-1.492)$ & 0.193 & $1.185(0.912-1.541)$ & 0.204 \\
\hline Neonatal complication & $1.008(0.778-1.305)$ & 0.953 & $0.920(0.695-1.217)$ & 0.558 \\
\hline
\end{tabular}

\section{Limitation}

- Conducted at different sites in which it was difficult to supervise timely.

- Geographical location was one factor during the follow up.

- Delayed to meet them during follow up b/c of the method of communication.

\section{Abbreviations}

ANC: antenatal care; EDHS: Ethiopian Demographic Health Survey; PPH: postpartum haemorrhage; WHO: World Health Organization.

\section{Authors' contributions}

AH was involved starting from developing of the proposal, tool, giving training, data cleaning, analysis and interpretation. $\mathrm{HH}$ drafted the manuscript and revised it critically in the design and analysis of the research. MM was involved mainly in statistical analysis, design and revising in draft of the manuscript and interpretation of the final result. BG was involved in revising the design and analysis of the research. All authors read and approved the final manuscript.

\section{Acknowledgements}

First and foremost we would like to thank to Department of Midwifery for giving us this opportunity to conduct the research. Similarly we would appreciate our friends who helped us in preparation of the proposal, tool and writing of the manuscript.

\section{Competing interests}

The authors declare that they have no competing interests.

\section{Availability of data and materials}

The data sets used during the current study are available from the corresponding author on reasonable request.

\section{Consent for publication}

Not applicable.

\section{Ethics approval and consent to participate}

Ethical clearance was obtained from Mekele University, College of Health Sciences Ethical review board. Permission letters were also sought from Tigray Regional education Bureau and the letter was distributed to each selected sites. Written Informed consent from the participants was obtained after clear explanation of the purpose of the study. For those whose age was less than
16 years old consent for participation was taken from their parents. Confidentiality and anonymity was maintained.

\section{Funding}

Mekele University with other partners was our fund agent to conduct this study. The role of Mekele University was providing appropriate training to develop the proposal, funding money to our data collectors and following how the study is going on, finally our University provides us basic training which was helpful for our study.

\section{Publisher's Note}

Springer Nature remains neutral with regard to jurisdictional claims in published maps and institutional affiliations.

Received: 6 November 2018 Accepted: 4 December 2018

Published online: 07 December 2018

\section{References}

1. Simkhada B, Teijlingen ER, Porter M, Simkhada P. Factors affecting the utilization of antenatal care in developing countries: systematic review of the literature. J Adv Nurs. 2008;61(3):244-60.

2. World Health Organization. World Health Statistics. 2012. apps.who.int/ iris/bitstream/10665/44844/1/9789241564441_eng.pdf.

3. Berhan Y, Berhan A. Review of maternal mortality in Ethiopia: a story of the past 30 years. Ethiop J Health Sci. 2014;24(1):3-14.

4. Abou-Zahr CL, Tessa M. Promises, achievements and missed opportunities: an analysis of trends, levels and differentials, 1990-2001.

5. Antenatal Care in Developing Countries Promises, achievements and missed opportunities. http://www.unicef.org/media/files/antenatal.pdf. Accessed 4 Apr 2017

6. Banda Isaac, Michelo Charles, Hazemba Alice. Factors associated with late antenatal care attendance in selected rural and urban communities of the copper belt province of Zambia. Med J Zambia. 2012;39(3):29-36.

7. Raatikainen $\mathrm{K}$, Heiskanen N, Heinonen S. Under-attending free antenatal care is associated with adverse pregnancy outcomes. BMC Public Health. 2007;7:268

8. Tariku Alemayehu, Melkamu Yilma, Kebed Zewditu. Previous utilization of service does not improve timely booking in antenatal care: cross sectional study on timing of antenatal care booking at public health facilities in Addis Ababa. Ethiop J Health Dev. 2010;24(3):226-33.

9. Tura G. Antenatal care service utilization and associated factors in Metekel Zone, Northwest Ethiopia. Ethiop J Health Sci. 2009;19:2.

10. Hamdela B, Godebo G, Gebre T. Predictors of early antenatal care booking in government health facilities of Hossana Town, Hadiya Zone, South Ethiopia: unmatched case control study. J AIDS Clin Res. 2015;6:521.

11. Damme TG, Workineh D, Gmariam A. Time of antenatal care booking and associated factors among pregnant women attending Ambo Town health facilities, Central Ethiopia. J Gynecol Obstetric. 2015;3(5):103-6. 
12. Gudayu TW. Proportion and factors associated with late antenatal care booking among pregnant mothers in Gondar Town, North West Ethiopia. Afr J Reprod Health. 2015;19(2):94-100.

13. Federal Democratic Republic of Ethiopia Ministry of Health., Health Sector Development Program IV 2010/11-2014/15. http://www.natio nalplanningcycles.org/sites/default/files/country_docs/Ethiopia/ethio pia_hsdp_iv_final_draft_2010_-2015.pdf.

14. Main D. The epidemiology of preterm birth. Clin Obstet Gynecol. 1988;31:5211-32

15. Harrson KA. Child bearing health and social priorities: a survey of 22,774 consecutive hospital births in Zaria, Northern Nigeria. Br J Obstet Gynecol. 1985;92(5):1-119.

16. Editorial. Why retained traditional birth attendants? Lancet. 1983; I: 223-4.

17. Editorial. Maternal health in sub Saharan Africa. Lancet. 1987; I: 255-7.

18. Harrison KA. The influence of maternal age and parity on child bearing with special reference to primigravida age 15 years and under. $\mathrm{Br} J$ Obstet Gynecol. 1985;92(5):23-31.

19. Orvos H, Hoffmann I. The perinatal outcome of pregnancy without prenatal care: a retrospective study in Szegd, Hungary. Eur J Obstetr Gynecol Reprod Biol. 2002;100:17.

20. Kapoor SK, Reddaiah VP, Lobo J. Antenatal care and perinatal mortality. Indian J Pediatr. 1985:52:159-62.
21. McCaw Binns A, Green Wood R, Asheley D, Golding J. Antenatal care and perinatal care in Jamaica: do they reduce perinatal death rates? Paediatr Perinat Epidemiol. 1994;8(1):86-97.

22. Villar J, Ba'aqeel $\mathrm{H}$, Piaggio G, et al. WHO antenatal care randomized trial for the evaluation of new model of routine antenatal care. Lancet. 2001;357:1551-64.

23. Carroli G, Villar J, Ba'aqeel H, Piaggio G, et al. WHO systematic review of randomized control trial of routine antenatal care. Lancet. 2001:357:1565-70.

24. Banta D. What is antenatal care? What are its boundaries? What is the effectiveness of antenatal care? What are the financial and organizational implications of antenatal care?. Geneva: WHO; 2003.

25. Abou-Zahr CL, Warlaw T. Antenatal care in developing countries-promises, achievements and missed opportunities: AN analysis of trends, levels and differentials, 1990-2001. Geneva: WHO; 2003.

26. Campbell OMR, Graham WJ. The lancet maternal survival series steering group strategies for reducing maternal mortality: getting on with what works. Lancet. 2006:368:1284-99.

27. Onwuhafua P, Adaze JA, et al. The effect of frequency of antenatal visit on pregnancy outcome in Kaduna, Nigeria. Trop J Obstetr Gynecol. 2017;33:155-64.
Ready to submit your research? Choose BMC and benefit from:

- fast, convenient online submission

- thorough peer review by experienced researchers in your field

- rapid publication on acceptance

- support for research data, including large and complex data types

- gold Open Access which fosters wider collaboration and increased citations

- maximum visibility for your research: over 100M website views per year

At BMC, research is always in progress.

Learn more biomedcentral.com/submissions 